\title{
RESEARCH
}

Open Access

\section{DCK is a promising prognostic biomarker and correlated with immune infiltrates in hepatocellular carcinoma}

Danjun Song ${ }^{1 \dagger}$, Yining Wang ${ }^{1 \dagger}$, Kai Zhu ${ }^{1 \dagger}$, Lingyu Tian ${ }^{1}$, Qiang Gao ${ }^{1,2}$, Jian Zhou ${ }^{1,2}$, Jia Fan $^{1,2}$ and Xiaoying Wang ${ }^{1 *}$ (i)

\begin{abstract}
Background: Deoxycytidine kinase (DCK), an enzyme in the nucleoside biosynthetic pathway, can affect the development of immune cells. However, the relationships between the expression of DCK, patient prognosis, and tumor-infiltrating immune cells (TIICS) in hepatocellular carcinoma (HCC) are still unclear.

Methods: The expression of DCK in HCC was analyzed through the Oncomine and Tumor Immune Estimation Resource (TIMER) databases. The impact of DCK on clinical prognosis was investigated via the Kaplan-Meier plotter and verified in the Gene Expression Profiling Interactive Analysis (GEPIA) databases. The interrelationships between DCK expression and TIICs in HCC were analyzed by the TIMER database. Additionally, the relationship between DCK expression and immune cell gene markers was calculated through TIMER and GEPIA databases.

Results: Compared with the adjacent normal tissues, high expression of DCK was observed in HCC tissues. Also, the higher expression of DCK was correlated to poorer prognosis in HCC patients, and it was associated with decreased survival in those with early stage and grade. Moreover, DCK expression was positively correlated with TIICS, including $\mathrm{CD}^{+}$and $\mathrm{CD} 8^{+} \mathrm{T}$ cells, B cells, monocytes, tumor-associated macrophages (TAMs), M1 and M2 macrophages, neutrophils, natural killer cells, and dendritic cells. Specifically, DCK expression levels were significantly associated with diverse immune gene marker sets, including those of Tregs and exhausted T cells.

(Continued on next page)
\end{abstract}

\footnotetext{
* Correspondence: xiaoyingwang@fudan.edu.cn

${ }^{\dagger}$ Danjun Song, Yining Wang and Kai Zhu contributed equally to this work. 'Department of Liver Surgery, Liver Cancer Institute, Zhongshan Hospital, Fudan University, Key Laboratory of Carcinogenesis and Cancer Invasion of Ministry of Education, Shanghai 200032, People's Republic of China Full list of author information is available at the end of the article
}

(c) The Author(s). 2020 Open Access This article is licensed under a Creative Commons Attribution 4.0 International License, which permits use, sharing, adaptation, distribution and reproduction in any medium or format, as long as you give appropriate credit to the original author(s) and the source, provide a link to the Creative Commons licence, and indicate if changes were made. The images or other third party material in this article are included in the article's Creative Commons licence, unless indicated otherwise in a credit line to the material. If material is not included in the article's Creative Commons licence and your intended use is not permitted by statutory regulation or exceeds the permitted use, you will need to obtain permission directly from the copyright holder. To view a copy of this licence, visit http://creativecommons.org/licenses/by/4.0/ The Creative Commons Public Domain Dedication waiver (http://creativecommons.org/publicdomain/zero/1.0/) applies to the data made available in this article, unless otherwise stated in a credit line to the data. 
(Continued from previous page)

Conclusion: These findings suggest that DCK expression is correlated with patient outcomes and tumor infiltration cell levels in HCC patients. Additionally, the increased level of DCK was associated with marker genes of Tregs and exhaustion-related inhibitory receptors, suggesting the potential role of DCK in immunosuppression and immune escape. These findings suggest that DCK can function as a potential novel prognostic biomarker and reflect the immune infiltration status in HCC patients.

Keywords: Deoxycytidine kinase, Hepatocellular carcinoma, Poor prognosis, Immune infiltration

\section{Introduction}

Hepatocellular carcinoma (HCC), one of the major primary hepatic tumors, is the fourth most common cause of cancer-related death worldwide [1]. HCC often develops from chronic liver inflammation, especially liver cirrhosis. The common risk factors for liver cancer are hepatitis $\mathrm{B} / \mathrm{C}$ virus infection, alcohol consumption, and non-alcoholic fatty liver disease. Although a remarkable advancement has been achieved in diagnosis, surgical treatment, adjuvant therapy, and immune therapy $[2,3]$, the prognosis after resection is unsatisfactory due to the high rate of recurrence $[4,5]$.

Deoxycytidine kinase $(D C K)$ is one of the essential enzymes of the nucleoside salvage pathway, and its expression is associated with the resistance to antiviral and anticancer chemotherapeutic agents [6-8]. DCK is highly expressed in lymphoid cells or tissues, such as thymus, spleen, lymph nodes, peripheral blood mononuclear cell, and bone marrow cells. Interestingly, $D C K$ was expressed differently in breast and pancreatic cancers, and the expression levels were associated with patient prognosis in both types $[9,10]$. A previous study analyzing eight microarray datasets comprising 521 human HCC tissues found that $D C K$ was upregulated in HCC tissues [11]. However, prognostic values and molecular mechanisms of $D C K$ in HCC are still unclear.

Tumor microenvironment and tumor-infiltrating immune cells (TIICs) are topics of interest and have shown an important role in cancer studies [12, 13]. Immune cells of tumor microenvironment play an important role in tumor progression in HCC. The immunosuppressive microenvironment of HCC contributes to immune tolerance and immune escape through different mechanisms [14]. DCK can have an impact on peripheral $\mathrm{T}$ cell homeostatic proliferation and survival, and its deficiency can influence lymphocyte development [15-17], indicating its potential role in the immune microenvironment. However, whether $D C K$ could influence immune cell and tumor microenvironment contributing to tumor progression still need investigation.

In this study, we investigated the expression level of $D C K$ and determined its correlation with cancer patient prognosis based on the online public databases such as the Oncomine, Kaplan-Meier plotter, Tumor Immune Estimation Resource (TIMER), and Gene Expression Profiling Interactive Analysis (GEPIA). Specifically, we analyzed the correlation between $D C K$ expression and TIICs in HCC through the TIMER database. The findings in this study showed the important role of $D C K$ in HCC and provided an interrelationship and an underlying mechanism between $D C K$ and TIIC interactions.

\section{Materials and methods}

\section{The expression of $D C K$}

The $D C K$ expression levels were analyzed in different cancer types using the Oncomine database (https://www. oncomine.org/resource/login.html) [18]. The parameters about the threshold were as follows: $p$ value of 0.05 , fold change of 1.5, and gene ranking of all. The results are exhibited as $p$ value, fold changes, and rank (\%).

\section{Prognosis analysis related to $D C K$ expression in HCC patients}

In order to determine the relationship between $D C K$ expression and patient prognosis, Kaplan-Meier plots (http://kmplot.com/analysis/) were used in the HCC [19]. For the expression of the DCK, the expression between the lower and upper quartiles was analyzed and the best performing threshold was applied as the final cutoff value automatically in the Cox regression analysis. The results were presented with the hazard ratio (HR) and $p$ values or Cox $p$ values from a log-rank test.

\section{Immune infiltration analysis related to the $D C K$ expression}

The TIMER database (https://cistrome.shinyapps.io/ timer/) [20] includes gene expression profiles and immune infiltration cells in 32 cancer types based on RNA-Seq expression profiling data from The Cancer Genome Atlas (TCGA) database. It can detect the differential gene expression in tumor tissues, analyze the infiltration of immune cells, and find the correlation between two genes through these profiles [21]. The infiltration levels of immune cells were analyzed through estimation by the statistical method through gene expression data. Therefore, we investigated the relationship between $D C K$ expression and TIICs, including $\mathrm{CD}^{+}$and $\mathrm{CD} 8^{+} \mathrm{T}$ cells, $\mathrm{B}$ cells, neutrophils, dendritic cells, and macrophages. Additionally, the correlations among $D C K$ expression and different gene markers of TIICs, like T cells, B cells, tumor-associated 
macrophages (TAMs), monocytes, M1 and M2 macrophages, natural killer (NK) cells, neutrophils, dendritic cells (DCs), T helper (Th) cells, T helper 17 (Th17) cells, follicular helper $\mathrm{T}$ (Tfh) cells, Tregs, and exhausted $\mathrm{T}$ cells, were analyzed. The marker genes of TIICs were reported as previous study [22].

\section{Gene correlation identification in GEPIA}

The GEPIA database (http://gepia.cancer-pku.cn/index. html) contains the gene expression data from TCGA and the Genotype-Tissue Expression (GTEx) projects [23]. It can also analyze differential gene expression, patient prognosis, and relationship of two genes through online data. Therefore, gene expression levels related to patient prognosis were identified via the GEPIA database, and the interrelationships between the levels of gene expression and TIICs were established. A median value of the DCK expression was used as a cutoff to distinguish high expression from low expression of DCK.

\section{Statistical analysis}

All statistical analyses were performed in R (version 3.5.2). Survival curves were generated by the Kaplan-Meier plots and GEPIA database. Forest plots were constructed using $\mathrm{R}$ package "forestplot" (https://cran.r-project.org/web/packages/forestplot/index.html). Spearman's correlation was used to evaluate the relation between gene expression and infiltrating immune cells. The strength of the correlation was defined as follows: 0.00-0.29 (weak), 0.30-0.59 (moderate), $0.60-0.79$ (strong), $0.80-1.00$ (very strong) [24]. $p$ values $<0.05$ were considered as statistically significant except for the correlation analysis.

\section{Results}

The expression levels of $D C K$ in HCC

A previous study has reported that metabolic gene $D C K$ was upregulated in the HCC tissues [11]. In order to validate the expression of $D C K$ between HCC tissues and adjacent normal tissues, gene expression analysis was analyzed via the Oncomine database. We found that $D C K$ expression was significantly higher in the HCC (Fig. 1a and Supplementary Table 1). Further evaluation of $D C K$ expression in HCC was calculated using the TIMER database, and consistent results were found for HCC (Fig. 1b). These findings validated that $D C K$ expression was highly expressed in HCC tissues.

\section{Prognostic values of $D C K$ expression in HCC}

Next, we investigated the relationship between the $D C K$ expression and prognosis in HCC using the Kaplan-Meier plotter database. Interestingly, a high expression of $D C K$ was associated with poorer prognosis in HCC patients (overall survival (OS): $\mathrm{HR}=1.90,95 \% \mathrm{CI}=1.32-2.72, p=$ $0.00043, n=364$; relapse-free survival (RFS): $H R=1.53$, 95\% CI $=1.10-2.13, p=0.011, n=316$; progression-free survival (PFS): $\mathrm{HR}=1.70,95 \% \mathrm{CI}=1.27-2.28, p=0.00034$, $n=370$; disease-specific survival (DSS): $\mathrm{HR}=2.02,95 \% \mathrm{CI}$ $=1.27-3.21, p=0.0026, n=362$; Fig. 2a-d). These findings indicated the potential prognostic values of $D C K$ in HCC. Also, we identified the relationship between the $D C K$ expression and prognostic values in HCC using the GEPIA database. The results showed that high expression of $D C K$ was associated with dismal prognosis in OS of HCC patients (Fig. 2e), but there was not statistical difference in PFS (Fig. 2f). These findings suggest that the expression of $D C K$ influences the prognosis of HCC patients.

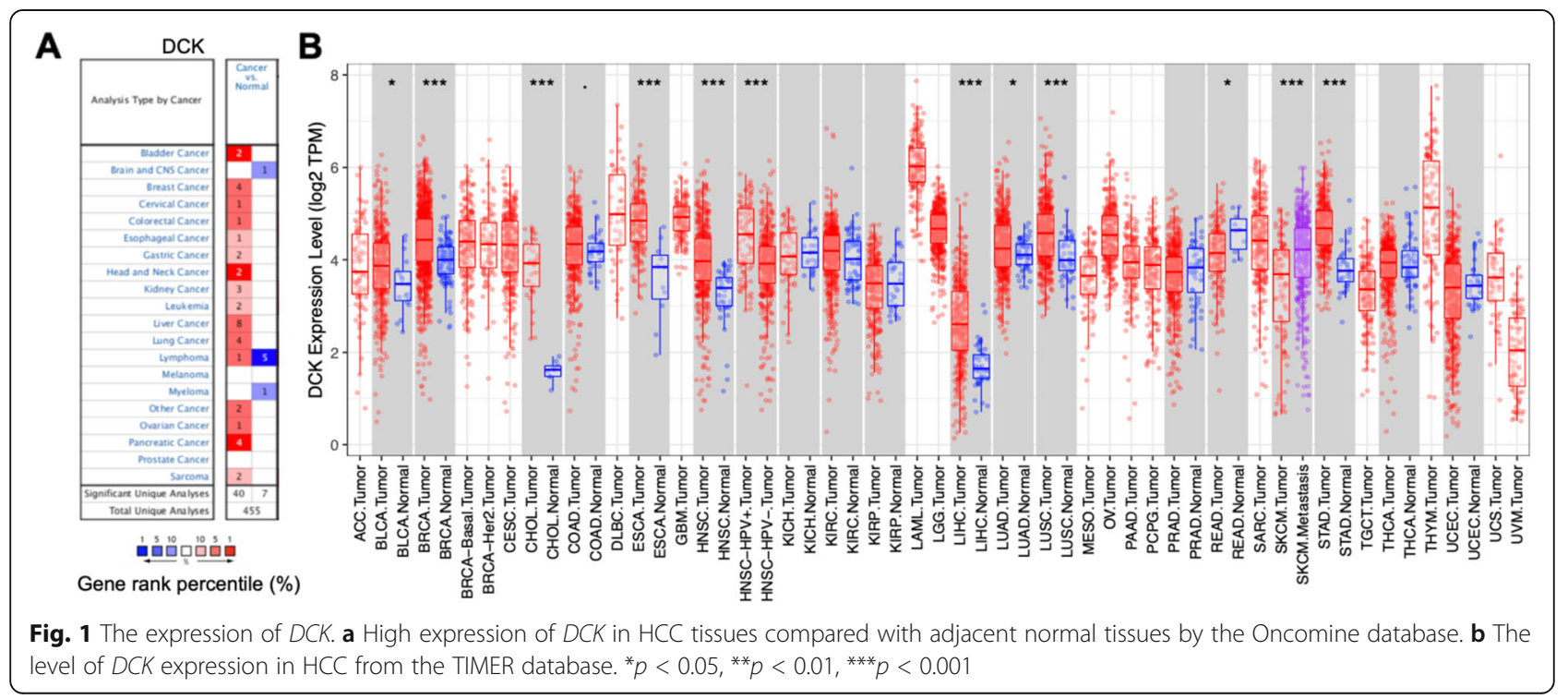




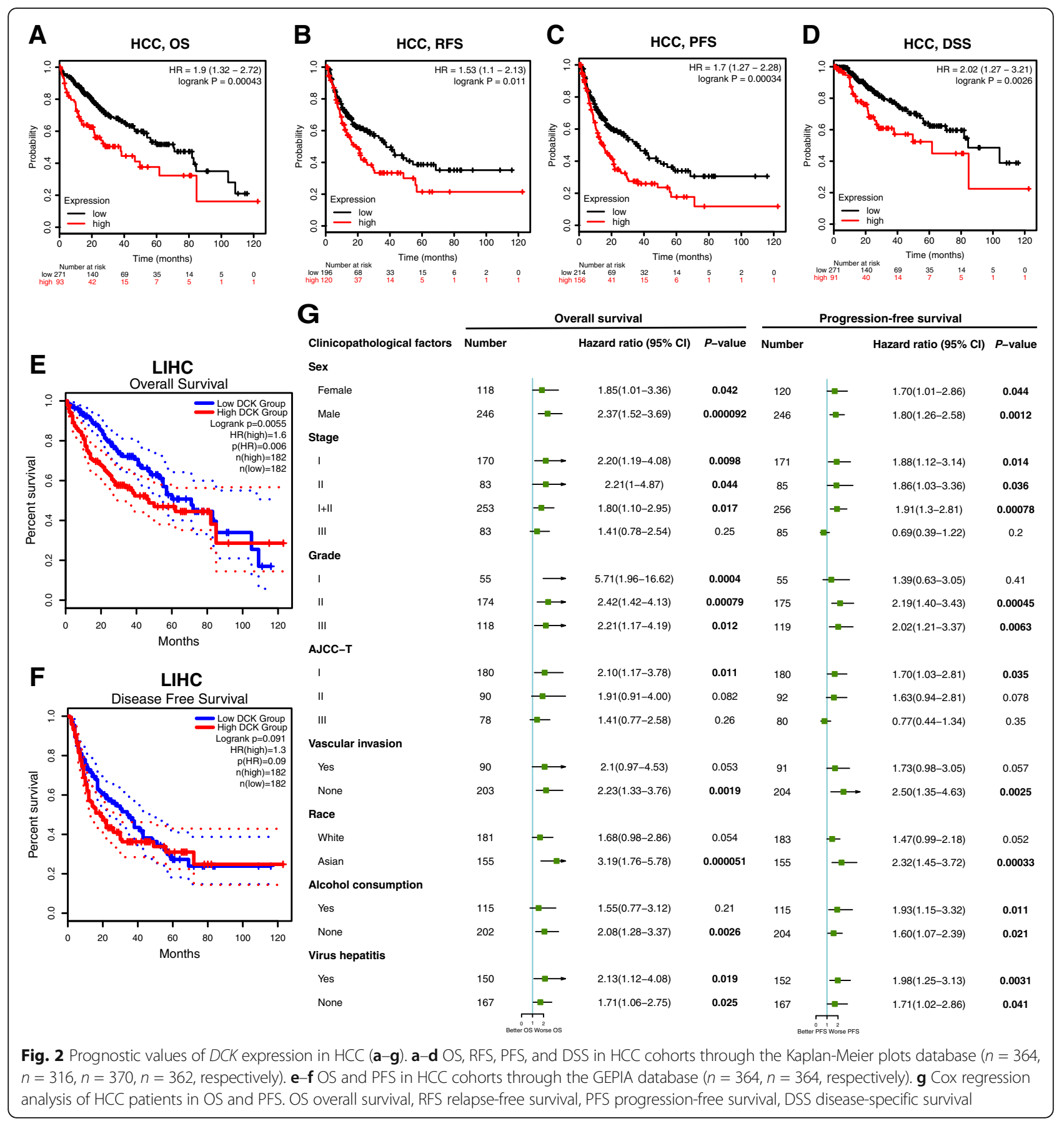

\section{High expression of $D C K$ related to clinical characteristics of HCC patients}

Based on the differential expression of $D C K$ and significant prognostic values related to its expression, which were observed in $\mathrm{HCC}$, we investigated the relationship between the expression of $D C K$ and different clinicopathological characteristics of HCC using the Kaplan-Meier plotter database. The high expression of DCK was related to worse OS and PFS rates in the females (OS: $\mathrm{HR}=1.85, p=0.042$; PFS: HR $=1.70, p=0.0013)$ and males (OS: $\mathrm{HR}=2.37, p=9.20 \times$
$10^{-5}$, PFS: $\mathrm{HR}=1.80, p=0.0012$ ), Asians (OS: $\mathrm{HR}=3.19, p$ $=5.10 \times 10^{-5}$; PFS: $\mathrm{HR}=2.32, p=0.00033$ ), non-alcoholics (OS: $\mathrm{HR}=2.08, p=0.0026$; PFS: $\mathrm{HR}=1.60, p=0.021$ ), patients with hepatitis viral infection (OS: $\mathrm{HR}=2.13, p=$ 0.019; PFS: $\mathrm{HR}=1.98, p=0.0031$ ) and those without it (OS: $\mathrm{HR}=1.71, p=0.025$; PFS: $\mathrm{HR}=1.71, p=0.041)$, and patients without vascular invasion (OS: $\mathrm{HR}=2.23, p=0.0019$; PFS: $\mathrm{HR}=2.50, p=0.025$ ) (Fig. $2 \mathrm{~g}$ ). Specifically, high expression of $D C K$ was correlated with poorer OS and PFS rates in stages I, II, and I+II, grades II and III, and AJCC-T 


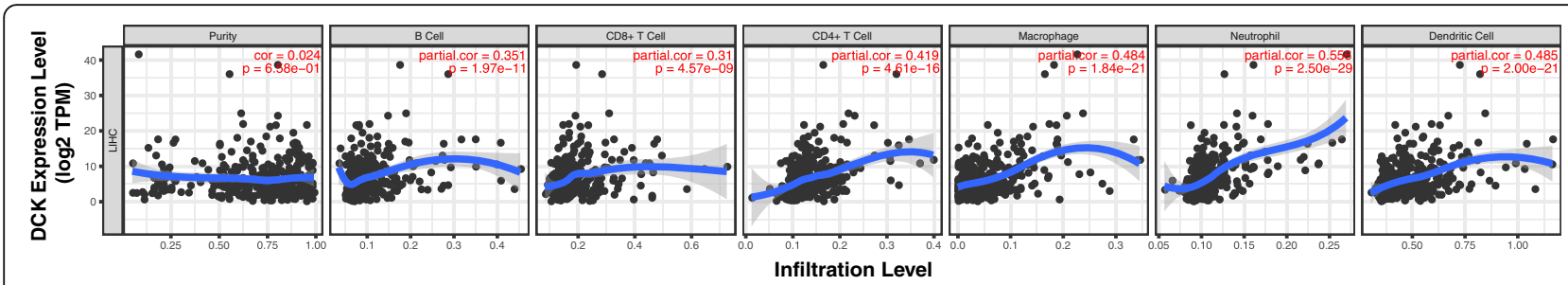

Fig. 3 Relationship between DCK expression and infiltration levels of immune cells in HCC via the TIMER database. The expression of DCK was significantly correlated with the infiltration levels of B cells, CD8 ${ }^{+} \mathrm{T}$ cells, $\mathrm{CD} 4^{+} \mathrm{T}$ cells, macrophages, neutrophils and dendritic cells in $\mathrm{HCC}$

stage I patients, but was not associated with stage III and AJCC-T II and III stages (Fig. 2g). These findings indicate that the expression level of $D C K$ can influence the prognosis in HCC patients with different clinicopathological factors, especially in these early-stage patients.

\section{$D C K$ expression levels are correlated with the immune infiltration in HCC}

Tumor-infiltrating lymphocytes influence the survival of patients with cancer. Therefore, the interrelationship between the TIICs and the $D C K$ expression was investigated by the TIMER database. The high expression of $D C K$ was related to patient outcomes in HCC, and it was correlated with high infiltration levels of immune cells (Fig. 3). The DCK expression was associated with dismal outcomes and positively correlated with the infiltration levels of B cells (cor $=0.351$, $\left.p=1.97 \times 10^{-11}\right), \mathrm{CD}^{+} \mathrm{T}$ cells $(\mathrm{cor}=0.310, p=4.57 \times$ $\left.10^{-9}\right), \mathrm{CD}^{+} \mathrm{T}$ cells $\left(\mathrm{cor}=0.419, p=4.61 \times 10^{-16}\right)$, macrophages $\left(\right.$ cor $=0.484, p=1.84 \times 10^{-21}$ ), neutrophils (cor = $\left.0.556, p=2.50 \times 10^{-29}\right)$, and dendritic cells (cor $=0.485, p$

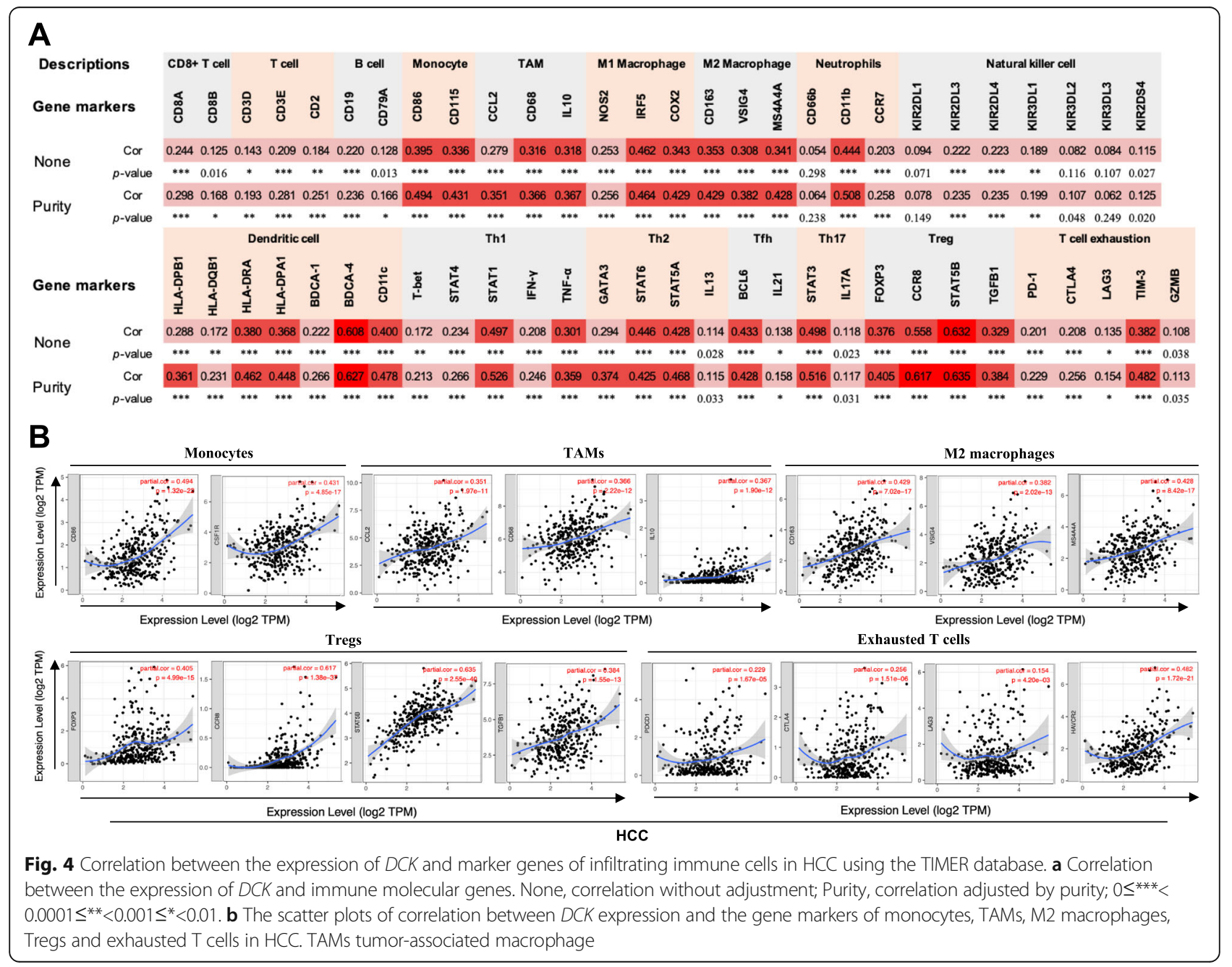


$=2.00 \times 10^{-21}$ ) in HCC (Fig. 3). These findings suggest immune infiltration may play a role in patient outcomes, and DCK could modulate immune infiltrating cells into HCC tissues. However, the expression of $D C K$ was not correlated with tumor purity ( $\operatorname{cor}=0.024, p=6.58 \times 10^{-1}$ ), suggesting the expression of $D C K$ was from cells in the tumor microenvironment.

\section{Correlation between $D C K$ expression and different gene markers of immune cell subsets}

We further investigated the relationships between $D C K$ expression and multiple TIICs in HCC through TIMER and GEPIA databases based on the different immune cell gene markers. The correlation was adjusted for tumor purity due to its influences on the immune infiltration analysis. The immune cells included $\mathrm{CD} 4^{+} \mathrm{T}$ cells, $\mathrm{CD} 8^{+}$ $\mathrm{T}$ cells, B cells, TAMs, monocytes, M1 and M2 macrophages, neutrophils, dendritic cells, and NK cells in HCC patients. Also, subsets of T cells, including Th1, Th2, Tfh, Th17, Tregs, and exhausted T cells, were investigated.

We found that the $D C K$ expression was significantly correlated with the expression of gene markers in monocytes, TAM, and M2 macrophages in HCC patients after adjusting tumor purity (Fig. 4a, b). DCK expression was significantly associated with subsets of $\mathrm{T}$ cells, revealing its association with cytokine secretion (Fig. 4a, b). Tregs have an essential role in immune escape and angiogenesis, and immune checkpoint regulation is important for $\mathrm{T}$ cell-mediated cancer-killing effect. Interestingly, the expression of $D C K$ was associated with the gene markers like CCR8, STAT5b, and TGFB1 of Tregs, and PD-1, CTLA-4, LAG3, TIM-3, and GZMB of exhausted T cells after adjusting tumor purity (Fig. 4a, b), revealing that increased expression of $D C K$ was associated with immunosuppression in HCC. These findings suggest that immune infiltrating cells could influence patient prognosis in HCC. Similar expression results were observed in GEPIA (Supplementary Table 2). The results strongly indicated the potential functions of $D C K$ in contributing to the angiogenesis and regulating immune escape in HCC.

\section{Discussion}

In this study, we demonstrate the $D C K$ expression and corresponding patient prognosis in HCC. DCK expression was significantly higher in HCC patients, and its high expression was correlated with worse long-term outcomes. To the best of our knowledge, this is the first study that reported a prognostic impact of $D C K$ in HCC. Moreover, high expression of $D C K$ was correlated with unfavorable prognosis for HCC patients, especially for those with early stage. Additionally, the expression of $D C K$ was correlated with TIICs and its marker genes in HCC. The increased level of $D C K$ was correlated with marker genes of Tregs and exhaustion-related inhibitory receptors, suggesting potential mechanisms of $D C K$ in immune escape. These findings demonstrate that $D C K$ can be a promising prognostic biomarker and is correlated with immune infiltrates in HCC.

As an essential enzyme in the nucleoside biosynthetic pathway, $D C K$ plays a role in metabolism and DNA synthesis during the embryogenesis, organogenesis, and essential cell developmental processes. The deficiency of $D C K$ in mice blocks the lymphocyte development and shows a significant decrease in both $\mathrm{T}$ and $\mathrm{B}$ cell populations compared with wild-type mice [17]. Mutation of $D C K$ impairs $\mathrm{T}$ and $\mathrm{B}$ cell function in mice, and mutant contains a $\mathrm{CD} 44^{\text {high }} \mathrm{CD} 62 \mathrm{~L}^{\text {low }}$ memory phenotype lymphocytes in the peripheral, with high levels of proliferation and apoptosis [15]. However, the activation of $D C K$ elevates the level of deoxyadenosine triphosphate (dATP) intracellularly, which suggests the link of $D C K$ activation to the induction of apoptosis. Therefore, differentially expressed $D C K$ in tumor tissues could influence the immune cell functions.

There is an urgent need for improving early diagnosis and treatment of HCC patients. The development of new biomarkers in detection, prognostic assessment, and treatment options should be a major research interest in the future [25]. The high expression of $D C K$ was observed in liver tumors, and its low expression was found in normal liver. The high expression of $D C K$ was correlated with dismal outcomes. Therefore, we have reason to believe that the $D C K$ could be a prognostic biomarker in HCC. Tumor microenvironment are important for tumor progression. Recent studies demonstrated that the integration of TIICs and clinicopathologic characteristics can be a prognostic predictive model and predict the response of immune therapy $[13,26]$. A positive correlation between the DCK expression and the TIICs indicates that $D C K$-based prediction of patient outcome in HCC may be associated with immune cell infiltration. Negative association between $D C K$ and tumor purity suggested that $D C K$ expression was from cells in the tumor environment. The expression of $D C K$ was more likely from TIICs [27]. Moreover, the expression of $D C K$ was associated with the expression of the immune cell markers, such as the markers of monocytes, TAM, M1, and M2 macrophages. These findings suggest the potential functions of $D C K$ in regulating infiltration and activity of macrophages. Furthermore, we observed that $D C K$ expression was relevant to the expression of markers of T cell subsets, like Th1, Th2, Tfh, and Th17, indicating its potential influence on the tumor progression in regulating the secretion of cytokines from the helper $\mathrm{T}$ cells.

Interestingly, the expression of $D C K$ was correlated with the marker genes of Tregs and exhaustion-related inhibitory receptors. Tregs play an important part in immune escape and angiogenesis, which could influence patient outcomes. Overexpression of inhibitory receptors in HCC 
can inhibit immune response and dampen $\mathrm{T}$ cell functions, resulting in tumor progression [28-31]. In return, the anti-immune-checkpoint inhibitor can provide HCC patients with a survival benefit [32]. These findings suggest the role of $D C K$ as an essential aspect in the immunosuppressive and immune escape and also indicate its potential function in regulating TIICs in HCC patients. Moreover, cytosolic $\mathrm{Ca}^{2+}$ ions are associated with the activity of $D C K$ in cells [33]. Altered $\mathrm{Ca}^{2+}$ flux could promote $\mathrm{T}$ cell subsets, which in turn promote cytokine production and downregulate CTLA-4 and $P D-1$ expression [34]. In addition, altered $\mathrm{Ca}^{2+}$ influences $\mathrm{Ca}^{2+} /$ cyclic AMP (cAMP) signaling pathway contributing to the regulation of cytokines [35]. Both the excretion of cytokines and change in CAMP pathway are associated with tumor progression $[12,36]$. These findings could be the potential mechanism of $D C K$ regulating the expression of inhibitor receptors and contributing to the progression of a tumor.

This study had several limitations. First, the role of $D C K$ was investigated through various datasets. Some potential basis still exists because of the different methods in data collection and analysis. Second, the correlation coefficients were not very strong. In fact, when analyzing the relationship between gene levels and TIICs, the correlation coefficients were mostly uncorrelated or had a weak and moderate correlation, and strong correlations were rare [22, 24]. Third, we only used public datasets, further identified by our HCC patient profiles, and the detailed relationship should be confirmed by in vitro or animal experiments. Additionally, comparing the efficiency between $D C K$ and traditional biomarkers in HCC should be further studied. The function of $D C K$ in other cancer types should be investigated in the future.

\section{Conclusions}

In conclusion, our results suggested that elevated $D C K$ expression levels were associated with dismal prognosis together with enhanced immune infiltration in HCC, and the increased level of $D C K$ was correlated with marker genes of Tregs and exhaustion-related inhibitory receptors, which could be the potential mechanism of $D C K$ affecting patient outcomes. Therefore, relatively high levels of $D C K$ in HCC could indicate the increased immune infiltration status and reflect a higher risk of death.

\section{Supplementary information}

Supplementary information accompanies this paper at https://doi.org/10. 1186/s12957-020-01953-1.

Additional file 1: Table S1. The expression of DCK in hepatocellular carcinoma versus normal tissues in the Oncomine database. Table S2. Correlation analysis between DCK and related genes and markers of immunes cells in GEPIA.

\section{Abbreviations}

DCK: Deoxycytidine kinase; TIICs: Tumor-infiltrating immune cells; TIME R: Tumor Immune Estimation Resource; GEPIA: The Gene Expression Profiling Interactive Analysis; HCC: Hepatocellular carcinoma; TAMs: Tumor-associated macrophages; TCGA: The Cancer Genome Atlas; NK cells: Natural killer cells; DCs: Dendritic cells; Th cells: T helper cells; Th17 cells: T helper 17 cells; Tfh cells: Follicular helper T cells; GTEx: The Genotype-Tissue Expression;

OS: Overall survival; RFS: Relapse-free survival; PFS: Progression-free survival; DSS: Disease-specific survival; cAMP: Cyclic AMP

\section{Acknowledgments}

Not applicable.

\section{Authors' contributions}

Conceptualization, W.X.Y.; data analysis, S.D.J., W.Y.N., and Z.K.; reference acquisition, S.D.J and T.L.Y; comments and suggestions, G.Q; administrative support, Z.J. and F.J.; manuscript drafting or revision, S.D.J., W.Y.N., and Z.K.; funding acquisition, W.X.Y. The author(s) read and approved the final manuscript.

\section{Funding}

This work was supported by the Shanghai Municipal Key Clinical Specialty and the National Natural Science Foundation of China (grant 81572367 and 81772556).

\section{Availability of data and materials}

All datasets used and/or analyzed during the current study are available from the public database.

Ethics approval and consent to participate

Not applicable.

Consent for publication

Not applicable.

\section{Competing interests}

The authors declare no conflicts of interest.

\section{Author details}

${ }^{1}$ Department of Liver Surgery, Liver Cancer Institute, Zhongshan Hospital, Fudan University, Key Laboratory of Carcinogenesis and Cancer Invasion of Ministry of Education, Shanghai 200032, People's Republic of China. ${ }^{2}$ Institutes of Biomedical Sciences, Fudan University, Shanghai, People's Republic of China.

Received: 18 May 2020 Accepted: 10 July 2020

Published online: 20 July 2020

\section{References}

1. Villanueva A. Hepatocellular carcinoma. New England J Med. 2019;380:145062.

2. Ishizawa T, Hasegawa K, Aoki T, Takahashi M, Inoue Y, Sano K, et al. Neither multiple tumors nor portal hypertension are surgical contraindications for hepatocellular carcinoma. Gastroenterology. 2008;134:1908-16.

3. Zhou J, Sun H-C, Wang Z, Cong W-M, Wang J-H, Zeng M-S, et al. Guidelines for diagnosis and treatment of primary liver cancer in China (2017 Edition). Liver cancer. 2018;7:235-60.

4. Hasegawa K, Kokudo N, Makuuchi M, Izumi N, Ichida T, Kudo M, et al. Comparison of resection and ablation for hepatocellular carcinoma: a cohort study based on a Japanese nationwide survey. J Hepatol. 2013;58: 724-9.

5. Han H-S, Shehta A, Ahn S, Yoon Y-S, Cho JY, Choi Y. Laparoscopic versus open liver resection for hepatocellular carcinoma: case-matched study with propensity score matching. J Hepatol. 2015;63:643-50.

6. Qin T, Jelinek J, Si J, Shu J, Issa J-PJ. Mechanisms of resistance to 5-aza-2'deoxycytidine in human cancer cell lines. Blood. 2009;113:659-67.

7. Dahn ML, Cruickshank BM, Jackson AJ, Dean C, Holloway RW, Hall SR, et al. Decitabine response in breast cancer requires efficient drug processing and is not limited by multidrug resistance. Mol Cancer Ther. 2020;19(5):1110-22 molcanther.0745.2019. 
8. Z Zhang Y, Lei Y, Xu J, Hua J, Zhang B, Liu J, et al. Role of Damage DNAbinding protein 1 in pancreatic cancer progression and chemoresistance. Cancers. 2019;11:1998.

9. Geutjes E-J, Tian S, Roepman P, Bernards R. Deoxycytidine kinase is overexpressed in poor outcome breast cancer and determines responsiveness to nucleoside analogs. Breast cancer research and treatment. 2012;131:809-18.

10. Sebastiani V, Ricci F, Rubio-Viqueira B, Kulesza P, Yeo CJ, Hidalgo M, et al. Immunohistochemical and genetic evaluation of deoxycytidine kinase in pancreatic cancer: relationship to molecular mechanisms of gemcitabine resistance and survival. Clin Cancer Res. 2006;12:2492-7.

11. Nwosu ZC, Megger DA, Hammad S, Sitek B, Roessler S, Ebert MP, et al. Identification of the consistently altered metabolic targets in human hepatocellular carcinoma. Cell Mol Gastroenterol Hepatol. 2017;4(2):303-323.e1.

12. Liu LZ, Zhang Z, Zheng BH, Shi Y, Duan M, Ma LJ, et al. CCL15 recruits suppressive monocytes to facilitate immune escape and disease progression in hepatocellular carcinoma. Hepatology. 2019;69:143-59.

13. Cabrita R, Lauss M, Sanna A, Donia M, Skaarup Larsen M, Mitra S, et al. Tertiary lymphoid structures improve immunotherapy and survival in melanoma. Nature. 2020;577:561-5.

14. Fu Y, Liu S, Zeng S, Shen H. From bench to bed: the tumor immune microenvironment and current immunotherapeutic strategies for hepatocellular carcinoma. J Exp Clin Cancer Res. 2019;38:396.

15. Choi O, Heathcote DA, Ho K-K, Müller PJ, Ghani H, Lam EWF, et al. A deficiency in nucleoside salvage impairs murine lymphocyte development, homeostasis, and survival. J Immunol (Baltimore, Md : 1950). 2012;188:3920-7.

16. Dobrovolsky VN, Bucci T, Heflich RH, Desjardins J, Richardson FC. Mice deficient for cytosolic thymidine kinase gene develop fatal kidney disease. Mol Genet Metab. 2003;78:1-10.

17. Toy G, Austin WR, Liao H-l, Cheng D, Singh A, Campbell DO, et al. Requirement for deoxycytidine kinase in $\mathrm{T}$ and $\mathrm{B}$ lymphocyte development. Proc Natl Acad Sci U S A. 2010;107:5551-6.

18. Rhodes DR, Kalyana-Sundaram S, Mahavisno V, Varambally R, Yu J, Briggs BB, et al. Oncomine 3.0: genes, pathways, and networks in a collection of 18,000 cancer gene expression profiles. Neoplasia (New York, NY). 2007;9: $166-80$.

19. Nagy Á, Lánczky A, Menyhárt O, Győrffy B. Validation of miRNA prognostic power in hepatocellular carcinoma using expression data of independent datasets. Sci Rep. 2018:8:9227.

20. Li T, Fan J, Wang B, Traugh N, Chen Q, Liu JS, et al. TIMER: a web server for comprehensive analysis of tumor-infiltrating immune cells. Cancer Res. 2017; 77:e108-10.

21. Li B, Severson E, Pignon J-C, Zhao H, Li T, Novak J, et al. Comprehensive analyses of tumor immunity: implications for cancer immunotherapy. Genome Biol. 2016;17:174.

22. Wu X, Qu D, Weygant N, Peng J, Houchen CW. Cancer stem cell marker DCLK1 correlates with tumorigenic immune infiltrates in the colon and gastric adenocarcinoma microenvironments. Cancers. 2020;12:274

23. Tang Z, Li C, Kang B, Gao G, Li C, Zhang Z. GEPIA: a web server for cancer and normal gene expression profiling and interactive analyses. Nucleic Acids Res. 2017:45:W98-W102.

24. Chen B, Lai J, Dai D, Chen R, Li X, Liao N. JAK1 as a prognostic marker and its correlation with immune infiltrates in breast cancer. Aging. 2019;11: 11124-35.

25. Zhou C, Liu C, Liu W, Chen W, Yin Y, Li C-W, et al. SLFN11 inhibits hepatocellular carcinoma tumorigenesis and metastasis by targeting RPS4X via mTOR pathway. Theranostics. 2020;10:4627-43.

26. Helmink BA, Reddy SM, Gao J, Zhang S, Basar R, Thakur R, et al. B cells and tertiary lymphoid structures promote immunotherapy response. Nature. 2020:577:549-55.

27. Spasokoukotskaja T, Arnér ES, Brosjö O, Gunvén P, Juliusson G, Liliemark J, et al. Expression of deoxycytidine kinase and phosphorylation of 2chlorodeoxyadenosine in human normal and tumour cells and tissues. Eur J Cancer. 1995;31a:202-8.

28. Wu K, Kryczek I, Chen L, Zou W, Welling TH. Kupffer cell suppression of CD8+ T cells in human hepatocellular carcinoma is mediated by B7-H1/ programmed death-1 interactions. Cancer Res. 2009;69:8067-75.

29. Kuang DM, Zhao Q, Peng C, Xu J, Zhang JP, Wu C, et al. Activated monocytes in peritumoral stroma of hepatocellular carcinoma foster immune privilege and disease progression through PD-L1. J Exp Med. 2009; 206:1327-37.
30. Li H, Wu K, Tao K, Chen L, Zheng Q, Lu X, et al. Tim-3/galectin-9 signaling pathway mediates T-cell dysfunction and predicts poor prognosis in patients with hepatitis B virus-associated hepatocellular carcinoma. Hepatology. 2012;56:1342-51.

31. Zhou G, Sprengers D, Boor PPC, Doukas M, Schutz H, Mancham S, et al. Antibodies against immune checkpoint molecules restore functions of tumor-infiltrating T cells in hepatocellular carcinomas. Gastroenterology. 2017;153:1107-1119.e1110.

32. Qin S, Ren Z, Meng Z, Chen Z, Chai X, Xiong J, et al. Camrelizumab in patients with previously treated advanced hepatocellular carcinoma: a multicentre, open-label, parallel-group, randomised, phase 2 trial. Lancet Oncol. 2020;21(4):571-80.

33. Keszler G, Spasokoukotskaja T, Csapo Z, Talianidis I, Eriksson S, Staub M, et al. Activation of deoxycytidine kinase in lymphocytes is calcium dependent and involves a conformational change detectable by native immunostaining. Biochem Pharmacol. 2004;67:947-55.

34. Rodríguez-Perea AL, Rojas M, Velilla-Hernández PA. High concentrations of atorvastatin reduce in-vitro function of conventional T and regulatory $T$ cells. Clin Exp Immunol. 2019:196:237-48.

35. Ahuja M, Chung WY, Lin WY, McNally BA, Muallem S. Ca(2+) signaling in exocrine cells. Cold Spring Harb Perspect Biol. 2019;12(5):a035279.

36. Liu H, Kuang $X$, Zhang $Y$, Ye $Y$, Li J, Liang L, et al. ADORA1 inhibition promotes tumor immune evasion by regulating the ATF3-PD-L1 axis. Cancer Cell. 2020;37:324-339.e328.

\section{Publisher's Note}

Springer Nature remains neutral with regard to jurisdictional claims in published maps and institutional affiliations.

\section{Ready to submit your research? Choose BMC and benefit from:}

- fast, convenient online submission

- thorough peer review by experienced researchers in your field

- rapid publication on acceptance

- support for research data, including large and complex data types

- gold Open Access which fosters wider collaboration and increased citations

- maximum visibility for your research: over $100 \mathrm{M}$ website views per year

At BMC, research is always in progress.

Learn more biomedcentral.com/submissions 